\title{
Güven Bölgesi Çerçevesi Tekniği ile MIMO Anten Dizisi Optimizasyonu ve SAR Hesaplaması
}

\author{
Ahmet Turgut $^{1 *}$, Begüm Korunur Engiz ${ }^{1}$ \\ 1*Ondokuz Mayıs Üniversitesi, Mühendislik Fakültesi, Elektrik Elektronik Mühendisliği Bölümü, Samsun, Türkiye (ORCID: 0000-0001-6729-0266) \\ ahmet.turgut@omu.edu.tr \\ ${ }^{1}$ Ondokuz Mayıs Üniversitesi, Mühendislik Fakültesi, Elektrik Elektronik Mühendisliği Bölümü, Samsun, Türkiye (ORCID: 0000-0002-3905-1791), \\ bkengiz@omu.edu.tr
}

(International Symposium on Multidisciplinary Studies and Innovative Technologies (ISMSIT) 2021 - 21-23 October 2021)

(DOI: $10.31590 /$ ejosat.1023275)

\begin{abstract}
ATIF/REFERENCE: Turgut, A. \& Korunur Engiz, B. (2021). Güven Bölgesi Çerçevesi Tekniği ile MIMO Anten Dizisi Optimizasyonu ve SAR Hesaplaması. Avrupa Bilim ve Teknoloji Dergisi, (29), 243-247.
\end{abstract}

\section{$\ddot{O} \mathbf{z}$}

Bu çalışmada, 5. nesil akıllı telefonlarda çoklu giriş çoklu çıkış (multiple-input multiple-output, MIMO) uygulamalar için $6 \mathrm{GHz}$ altı spektrumda (LTE bantları 42/43 ve LTE band 146) çalışan bir anten dizisi optimize edilerek özgül soğurma oranı (Specific Absorbtion Rate, SAR) değerleri hesaplanmıştır. Güven bölgesi Çerçevesi Optimizasyonu (Trust Region Framework) kullanılarak anten yeniden boyutlandırılmıştır. Elde edilen yeni anten boyutlarıyla, -6 dB'deki bant genişlikleri, LTE $42 / 43$ ve LTE 46 bant genişliklerine daha yakın değerlerle elde edilmiştir. S-parametrelerinde gerekli iyileştirmeler yapılan 10'lu anten dizisi ve hesaplamalı yetişkin erkek, yetişkin kadın ve çocuk modelleri kullanılarak, özgül soğurma oranı (Specific Absorbtion Rate, SAR) değerleri benzetimlerle hesaplanmış; yaş, cinsiyet ve doku kaynaklı farklılıklar belirlenmiştir. SAR hesaplamaları $3600 \mathrm{MHz}$ ve $5537.5 \mathrm{MHz}$ frekanslarında, her bir anten elemanı için ayrı ayrı gerçekleştirilerek, tüm kafa bölgesinde, beyin, deri ve kemik dokularında oluşan SAR değerlerinin karşılaştırması yapılmıştır. $3600 \mathrm{MHz}$ frekansında tüm kafa bölgesinde oluşan en yüksek SAR $(10 \mathrm{~g})$ değerleri sırasıyla çocuk, yetişkin erkek ve yetişkin kadın modelleri için $1.7 \mathrm{~W} / \mathrm{kg}, 1.19 \mathrm{~W} / \mathrm{kg}$ ve $0.39 \mathrm{~W} / \mathrm{kg}$ olarak hesaplanmıştır. $5537.5 \mathrm{MHz}$ frekansında ise, en yüksek SAR(10g) değeri yetişkin kadın ve erkek için $0.81 \mathrm{~W} / \mathrm{kg}$ iken bu değer çocuk modeli için $0.67 \mathrm{~W} / \mathrm{kg}$ 'dır. Beyin, deri ve kemik dokuları için ise SAR $(10 \mathrm{~g})$ değerleri sırasıyla $0.26-1.7 \mathrm{~W} / \mathrm{kg}, 0.30-1.7 \mathrm{~W} / \mathrm{kg}$ ve $0.39-1.7 \mathrm{~W} / \mathrm{kg}$ arasında değişmektedir.

Anahtar Kelimeler: MIMO, Anten Dizisi, 5. Nesil, Güven Bölgesi Çerçevesi, Özgül Soğurma Oranı

\section{MIMO Antenna Array Optimization with Trust Region Framework Technique and SAR Calculation}

\begin{abstract}
In this study, an antenna array operating in the sub-6 GHz spectrum (LTE bands 42/43 and LTE band 46) for multiple-input multipleoutput (MIMO) applications on 5G smartphones was optimized and the specific absorption rate (SAR) values have been calculated. Antenna resized using Trust Region Framework Optimization. With the new antenna dimensions obtained, bandwidths at $-6 \mathrm{~dB}$ were achieved with values closer to LTE 42/43 and LTE 46 bandwidths. The specific absorption rate (SAR) values were calculated using the antenna array whose s-parameters were optimized and computational adult male, adult female and child models through simulations; age, gender and tissue related differences were determined. SAR calculations were performed separately for each antenna element at $3600 \mathrm{MHz}$ and $5537.5 \mathrm{MHz}$ frequencies, and the SAR values in the entire head region, brain, skin and bone tissues were compared. The highest $\mathrm{SAR}(10 \mathrm{~g})$ values in the entire head region at $3600 \mathrm{MHz}$ were calculated as $1.7 \mathrm{~W} / \mathrm{kg}, 1.19 \mathrm{~W} / \mathrm{kg}$ and 0.39 $\mathrm{W} / \mathrm{kg}$ for the child, adult male and adult female models, respectively. At the frequency of $5537.5 \mathrm{MHz}$, the highest $\mathrm{SAR}(10 \mathrm{~g}) \mathrm{value}$ is $0.81 \mathrm{~W} / \mathrm{kg}$ for adult men and women, while this value is $0.67 \mathrm{~W} / \mathrm{kg}$ for the child model. The SAR(10g) values for brain, skin and bone tissues vary between $0.26-1.7 \mathrm{~W} / \mathrm{kg}, 0.30-1.7 \mathrm{~W} / \mathrm{kg}$ and $0.39-1.7 \mathrm{~W} / \mathrm{kg}$, respectively.
\end{abstract}

Keywords: MIMO, Antenna Array, 5G, Trust Region Framework, Specific Absorbtion Rate

*Sorumlu Yazar: ahmet.turgut@ omu.edu.tr 


\section{Giriş}

Günümüzde akıllı telefonlar iletişim özelliklerinin yanında, nesnelerin interneti (IoT), eğlence, finansal hizmetler ve navigasyon gibi çok yönlü işlevleri nedeniyle giderek daha popüler hale gelmektedir (Kumar et al., 2021). Bu nedenle çok sayıda hizmeti desteleyen haberleşme sistemlerinin tasarımı ve geliştirilmesi üzerine çok sayıda çalışmalar yapılmaya başlanmıştır. Çoklu giriş çoklu çıkış (multiple-input multipleoutput, MIMO) teknolojisi, çok yollu girişimin olumsuz etkilerini azaltma ve sistem kapasitesini artırma özellikleriyle yaygın olarak kullanılmaktadır. MIMO teknolojisi, çok sayıda antenin tek bir kablosuz cihaza yerleştirilmesinden oluşmaktadır ve beşinci nesil (fifth generation, 5G) iletişim sistemlerinin gerçekleştirilmesi için önemli bir teknolojidir. Bununla birlikte, kablosuz iletişim teknolojilerinin ilerlemesi genel halkın daha yüksek seviyelerde elektromanyetik (EM) dalgalara maruz kalma durumunu beraberinde getirmektedir. $\mathrm{Bu}$ nedenle radyo frekansında, EM dalgaların insan sağlığı üzerinde olası etkilerinin tespit edilmesi gerekmektedir. İnsan vücudu tarafından emilen EM enerji miktarı olan özgül soğurma oranı (Specific Absorbtion Rate, SAR) değeri, bu tespitin yapılabilmesi için son derece önemlidir.

5G akıllı telefonlar için, portlar arasında yüksek izolasyon ve verimliliğe sahip kompakt, geniş bantlı anten sistemleri gerekmektedir (Sun et al., 2018). Yakın geçmişte, $6 \mathrm{GHz}$ altı spektrum için, 5G akıllı telefonlar için çeşitli MIMO anten sistemleri önerilmiştir (Parchin et al., 2019; Li et al., 2017; Zhao et al., 2018; Wong et al., 2016). Bu çalışmalarda sunulan akıllı telefon antenleri, baskılı devre kartında geniş alan kaplamaktadır. Bunun yanında, bant genişliğinin az olması ( $<200 \mathrm{MHz})$ ve tek bantlı çalışmaya olanak tanıması nedeniyle sistem karmaşıklığı artmakta ve üretim zorlaşmaktadır. 5G akıllı telefonlarda kullanılan antenlerin, daha iyi MIMO performansı sergileyebilmesini sağlamak ve anten sayısını artırmak için daha küçük boyutlarda tasarlanması gerekmektedir. Sistem kartında fazla sayıda anten olması durumu ise genel sistemi bozmasının yanında ciddi izolasyon problemlerine sebep olmaktadır. (Zou et al., 2018; Dong et al., 2020; Li et al., 2018)'da incelenen antenlerin çoğu, -6 dB'den küçük yansıma katsayısına sahipken, $13 \mathrm{~dB}$ 'den daha iyi izolasyon değerlerine sahiptir. (Zou et al., 2018)'de $3400 \mathrm{MHz}-3600 \mathrm{MHz}$ ve $5150 \mathrm{MHz}-5925 \mathrm{MHz}$ frekans aralıklarında çalışan sekiz portlu bir MIMO anten sistemi önerilmektedir. Bu anten alt bantta $-10 \mathrm{~dB}$ bant genişliği sağlarken, yüksek bantta $-6 \mathrm{~dB}$ empedans bant genişliği sunmaktadır. LTE 42 ve LTE 43'ü kapsayabilen geniş bir empedans bant genişliği elde etmek için tasarlanan 10'lu anten dizisi (Wong et al., 2015)'de önerilmiştir. $\mathrm{Bu}$ 10'lu anten dizisinin $20 \mathrm{~dB}$ sinyal gürültü oranındaki (Signal to Noise Ratio, SNR) $10 \times 10$ MIMO kanal kapasitesi, 47 bps/Hz'e kadar ulaşabilmektedir.

Bu çalışmada (Li et al., 2018)' de tasarlanan ve gerçeklenen çok bantlı ve çok modlu 10'lu anten dizisi güven bölgesi çerçevesi (Trust Region Framework) optimizasyonu kullanılarak CST (Computer Simulation Technology) ortamında yeniden boyutlandırılmış ve bu yeni anten dizisi SAR hesaplamalarında kullanılmıştır. Her bir dizi elemanı çift modlu $\mathrm{T}$ şeklinde bir yuva anteninden oluşan bu anten, düşük bantta LTE 42/43'ü (3400-3800 MHz), yüksek bantta ise LTE 46'yı (5150-5925 $\mathrm{MHz}$ ) desteklemektedir. Gerçekleştirilen optimizasyonun ardından, 10'lu anten dizisi için SAR değerleri hesaplanmıştır.
Akıllı telefonlardan kaynaklanan SAR değerleri ve bu değerlerin azaltılmasına yönelik anten tasarımı içeren çalışmalarda SAR değerleri genellikle fantom kullanılarak hesaplanmıştır (Koga et al., 2016; Zhao et al., 2013) ve SAR değerlerini anatomik olarak gerçekçi hesaplamalı insan modellerinde inceleyen çok az sayıda çalışma bulunmaktadır (Takei et al., 2017). Bu nedenle bu çalışmada 10'lu anten dizisinin SAR değerleri, $3600 \mathrm{MHz}$ ve $5537.5 \mathrm{MHz}$ frekanslarında yetişkin erkek, yetişkin kadın ve çocuk hesaplamalı insan modellerinde tüm kafa ve farklı dokular (beyin, deri ve kemik) için hesaplanmış, sonuçlar karşılaştırılmış ve böylece yaş, cinsiyet ve doku kaynaklı farklılıklar belirlenmiştir.

\section{Materyal ve Metot}

\subsection{Anten Geometrisi}

$\mathrm{Bu}$ çalışmada, güven bölgesi çerçevesi algoritması kullanılarak (Li et al., 2018)' de tasarlanan 10'lu anten dizisinin optimizasyonu gerçekleştirilmiştir. $\mathrm{Bu}$ anten dizisinin her bir elemanı yarı (slot) antendir ve LTE $42 / 43$ ve LTE 46 bantlarında çalışmaktadır. Optimizasyon işleminden önce Şekil 1.a'da verilen örnek anten elemanındaki, s-parametrelerinde değişime neden olabilen uzunluklar belirlenmiştir.

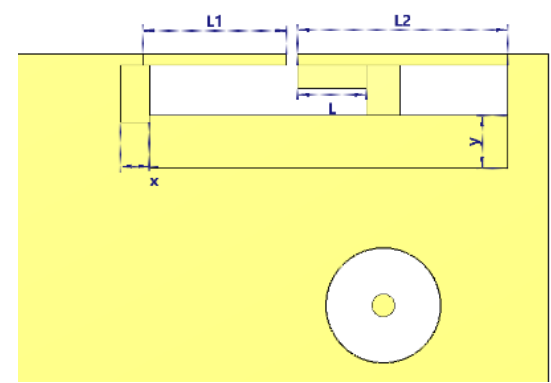

(a)

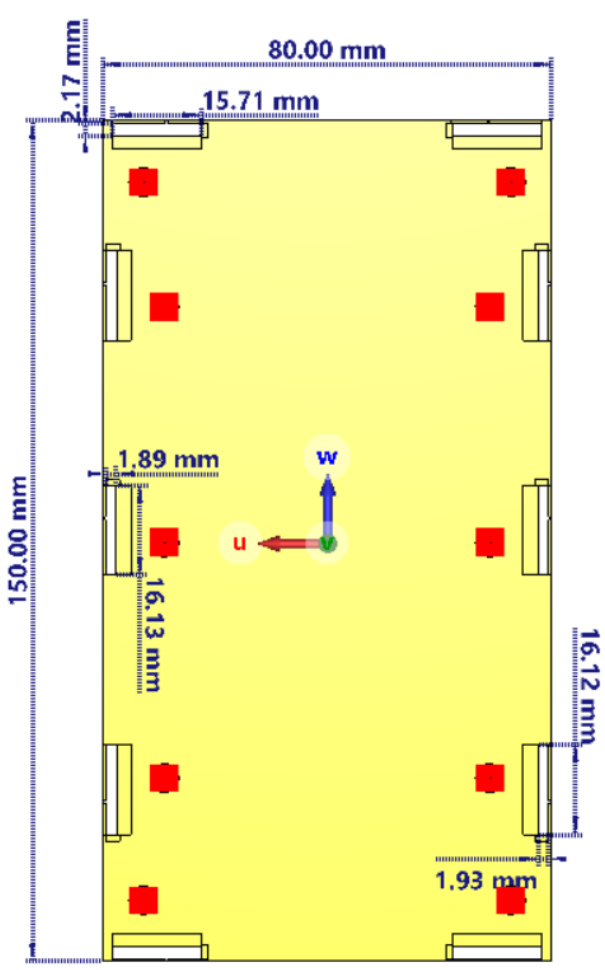

(b)

Şekil 1. a) Yarık anten elemanının detaylı görünümü b) 10'lu anten dizisinin genel yapisı 
L1-L2 uzunluklarındaki dar şerit kısmını ve bu uzunluklara bağlı olarak L uzunluğundaki besleme şeridinin kısa ayar bölümünü oluşturan parça boyutları benzetim programında rahatlıkla değiştirilebilecek hale getirilmiştir. Bunun yanında boşluk ölçülerinde değişkenliği sağlayabilmek için; Şekil 1.a'da görüldüğü gibi, $\mathrm{x} \mathrm{mm}$ uzunluğunda ve y $\mathrm{mm}$ genişliğinde parçalar toprak bölümünden ayrılmıştır. $\mathrm{Bu}$ işlemler anten dizisini oluşturan her bir anten elemanı için uygulanmıştır. Güven bölgesi çerçevesi optimizasyonuna değişken olarak girilen L1, L2, $\mathrm{x}$ ve y uzunlukları program tarafindan sistematik olarak değiştirilerek, $3400 \mathrm{MHz}-3600 \mathrm{MHz}$ ve $5150 \mathrm{MHz}-5925$ $\mathrm{MHz}$ frekans aralıklarında çalışan anten için daha uygun sparametreleri elde edilmiştir. Optimizasyon sonucunda yeni boyutları belirlenen antenin geometrisi ve fiziksel boyutları Şekil 1.b'de verilmiştir. Anten dizisini oluşturan elemanlar; kayıplı FR4 taban malzemesinin (bağıl geçirgenlik: 4.3 ve kayıp tanjantı: 0.025$)$ üst, alt, sağ ve sol kenarlarında bulunmaktadır. Taban malzemesinin boyutları $(150 \mathrm{~mm} \times 80 \mathrm{~mm} \times 0: 8 \mathrm{~mm})$ olup, 5.7 inç akıllı telefonlarla uyumludur.

\subsubsection{Yarkk Antenin Özellikleri ve Optimizasyonu}

Tasarımda referans alınan MIMO siteminde, antenlerin ana yayıcı olarak çalışması için toprak düzlemi üzerinde $16 \mathrm{~mm} \mathrm{x}$ $2.5 \mathrm{~mm}$ boyutlarında, dikdörtgen şeklinde boşluklar açılmış PCB'nin kenarı boyunca oluşturulan $0,5 \mathrm{~mm} \times 0,5 \mathrm{~mm}$ boyutlarındaki açıklıklar ile boşluğun $\mathrm{T}$ şeklini alması sağlanmıştır. Böylece bu şerit, L1 uzunluğunda kısa ve L2 uzunluğunda uzun şeritten oluşan iki bölüme ayrılmıştır. Referans antenin yeni boyutları güven bölgesi çerçevesi optimizasyonu ile belirlenirken $0,5 \mathrm{~mm}$ x $0,5 \mathrm{~mm}$ boyutlarındaki açıklık sabit tutulmuş, her bir yarık anten elemanında $x, y, L 1$, L2 ve L değerleri hesaplanmıştır. Optimizasyon sonucunda elde edilen $\mathrm{x}, \mathrm{y}, \mathrm{L} 1, \mathrm{~L} 2$ ve $\mathrm{L}$ değerleri Tablo 1'de verilmiştir. 10'lu anten dizisi düşük ve yüksek bantlarda çalışacağı için, her bir yarık anten elemanı için parametreleri ayrı ayrı hesaplanmıştır. Boyutları yeniden hesaplanan bu anten dizisinin yatay ve dikey eksende simetrik olduğu için, dizinin sol tarafinda yer alan antenlere ilişkin uzunluklar Tablo 1.'de verilmiştir.

Tablo 1. Her bir anten için yarık boyutları

\begin{tabular}{|c|c|c|c|c|c|}
\hline Parametreler & $\begin{array}{c}\boldsymbol{x} \\
(\mathbf{m m})\end{array}$ & $\begin{array}{c}\boldsymbol{y} \\
(\mathbf{m m})\end{array}$ & $\begin{array}{c}\mathbf{L} \\
(\mathbf{m m})\end{array}$ & $\begin{array}{c}\mathbf{L 1} \\
(\mathbf{m m})\end{array}$ & $\begin{array}{c}\mathbf{L 2} \\
(\mathbf{m m})\end{array}$ \\
\hline Anten 1 & 1.29 & 2.33 & 3 & 6 & 9.20 \\
\hline Anten 2 & 1.08 & 2.57 & 3.71 & 5.71 & 9.91 \\
\hline Anten 3 & 0.97 & 2.61 & 3.81 & 5.72 & 9.91 \\
\hline Anten 4 & 1.08 & 2.57 & 3.71 & 5.71 & 9.91 \\
\hline Anten 5 & 1.29 & 2.33 & 3 & 6 & 9.20 \\
\hline
\end{tabular}

Optimize edilen MIMO anten dizisinin s-parametreleri (yansıma katsayıları ve iletim katsayıları) CST STUDIO SUITE 2021 programıla hesaplanmış ve Şekil 2. a'da verilmiştir. Şekilden de görüldüğü gibi, sırasıyla düşük bandı ve yüksek bandı kapsayacak şekilde yaklaşık olarak $3600 \mathrm{MHz}$ ve 5537.5 $\mathrm{MHz}$ frekanslarında iki farklı rezonans modu oluşturulmuştur. -6 dB'deki (3:1 voltaj duran dalga oranı, VSWR) empedans bant genişlikleri sırasıyla $3401.7 \mathrm{MHz}-3836.7 \mathrm{MHz}$ ve $5084.9 \mathrm{MHz}-$ 5927.1 MHz'dir. Bu bant genişlikleri, anten dizisinin kapsaması beklenen bantlarda (LTE 42/43 ve LTE46), optimizasyon öncesine göre (3386 MHz-3830 MHz ve $5078 \mathrm{MHz}-5984 \mathrm{MHz}$ ) daha uygun değerlerin elde edildiğini ortaya koymaktadır. Şekil 2. b'de ise yüksek bant boyunca izolasyonların $13.454 \mathrm{~dB}$ 'den, düşük bantta ise $9.9432 \mathrm{~dB}$ 'den daha iyi olduğu görülmektedir. $\mathrm{Bu}$ değerler 5G MIMO antenler için kabul edilebilir değerlerdir.
Şekil 2'den de görüldüğü gibi, yeni MIMO anten dizisinin empedans bant genişliği ve izolasyon seviyeleri oldukça iyidir ve optimizasyon işlemi ile referans antene göre (Li et al., 2018) iyileşme sağlanmıştır.
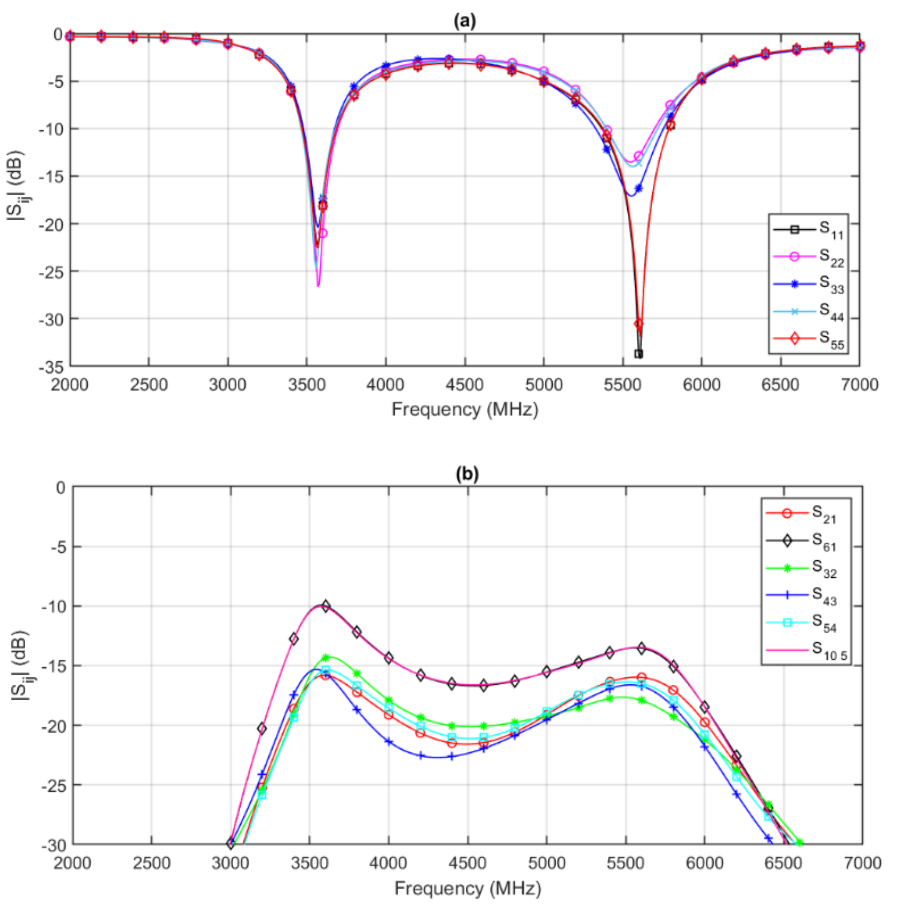

Şekil 2. Benzetim sonucunda elde edilen s-parametreleri (a)Yansıma katsayıları (b) Iletim katsayıları

\subsubsection{Güven Bölgesi Çerçevesi Optimizasyonu}

Anten tasarımında kullanılan güven bölgesi çerçevesi optimizasyonu ile başlangıç noktasının çevresindeki bir "güven" bölgesinde, birincil veriler üzerinden doğrusal bir model oluşturulmaktadır. Modellenen çözüm, verilerin doğru bir modeline yakınsayana kadar yeni başlangıç noktası olarak kullanılmakta, benzetim sayısını azaltmak ve optimizasyon sürecini hızlandırmak için s-parametresi hassasiyet bilgisinden yararlanılmaktadır. Bu çalışmada, 10'lu anten dizisine ait her bir yarık anten elemanı için -6 dB'deki bant genişliklerinin 3400 MHz-3800 MHz ve $5150 \mathrm{MHz}-5925 \mathrm{MHz}$ frekans bantlarına en yakın değerlerde olması ve yansıma katsayılarının $\left(S_{11}, S_{22}, \ldots\right.$, $\mathrm{S}_{1010}$ ) daha uygun değerlerde olması hedeflenmiş̧ir. $\mathrm{Bu}$ amaç için, $x, y, L, L 1$ ve L2 değerleri güven bölgesi çerçevesi algoritması kullanılarak değiştirilmiş ve en uygun uzunluklar belirlenmiştir. Deneme yanılma yöntemine alternatif olarak kullanılabilecek, en uygun sonuca çok daha hızlı ve sistematik bir biçimde ulaşmayı sağlayan bu optimizasyon yöntemi ile farkl 1 anten geometrilerinde istenen frekans aralıklarına en uygun s-parametrelerinin elde edilebileceği gösterilmiştir. Şekil 3'de optimizasyonu yapilan yeni $10^{\prime}$ lu anten dizisinin, xy düzleminde 3600 MHZ'de, Şekil 4'de 5537.5 MHz'de farklı boyuttaki üç anten elemanının benzetim yoluyla elde edilen ışıma örüntüleri verilmiştir. Önerilen yeni anten simetrik olduğundan, diğer anten bileşenlerinin 1şıma örüntülerine yer verilmemiştir. Şekilden görüldüğü gibi üç anten elemanı da çalışma bant genişliği üzerinde çok yönlü ışıma örüntüsüne sahiptir. 

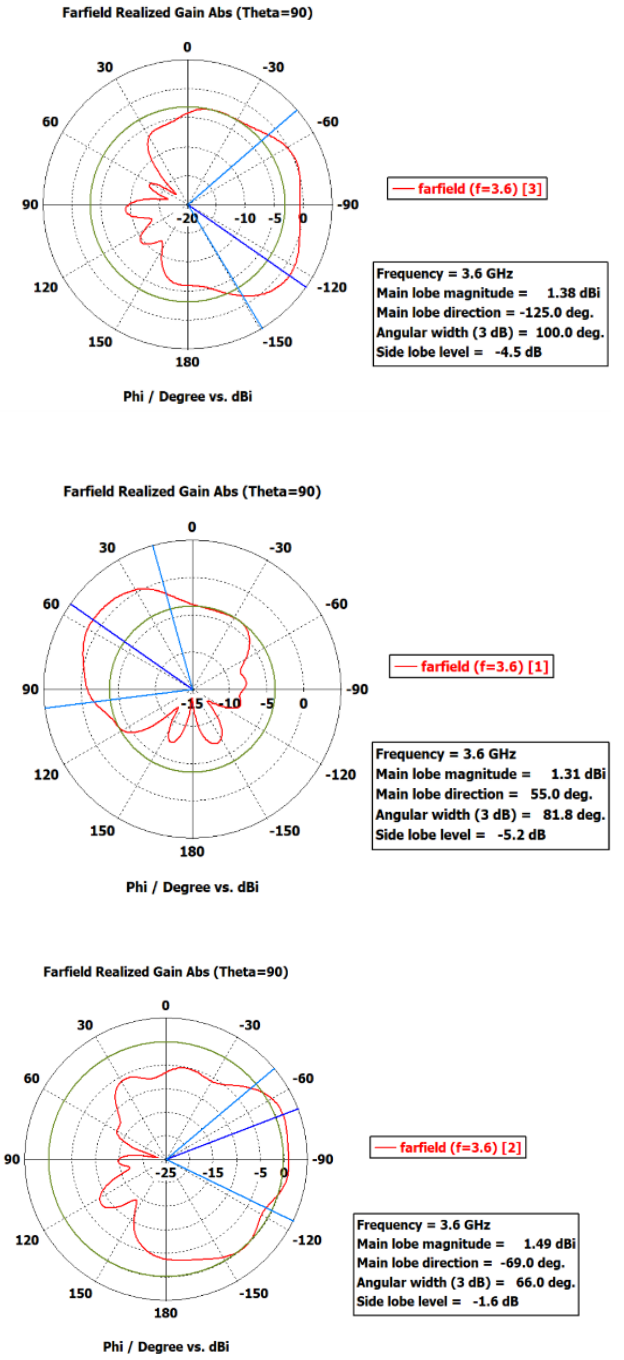

Şekil 3. $3600 \mathrm{MHz}$ 'de 3 farkll yarı anten elemanı için, iki boyutlu ışıma örüntüsü
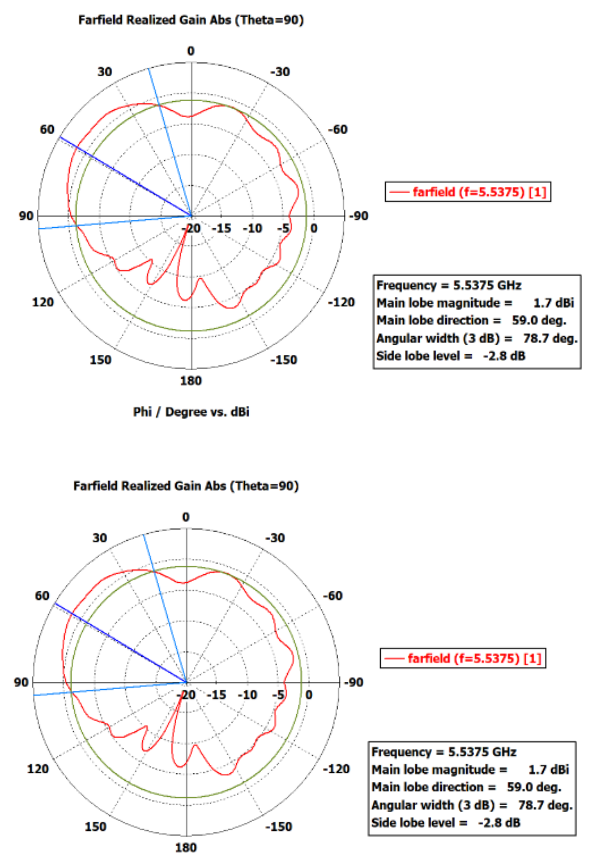

e-ISSN: 2148-2683

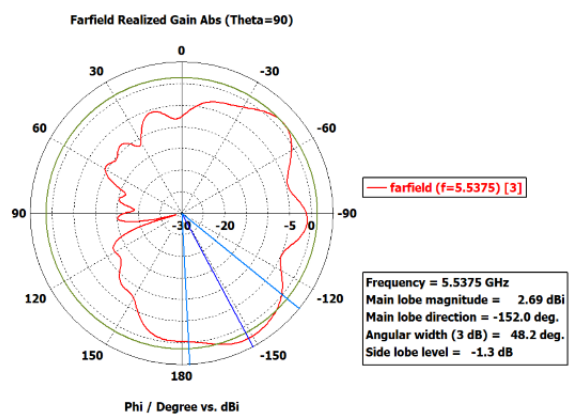

Şekil 4. $5537.5 \mathrm{MHz}$ 'de 3 farkl yarı anten elemanı için, iki boyutlu ışıma örüntüsü

\section{Benzetim Sonuçları}

Bu çalışmada, benzetimi yapılan yeni $10^{\prime} l u$ anten dizisinin SAR (10g) hesaplamaları, farklı hesaplamalı insan modelleri, farklı dokular ve frekanslar için (3600 MHZ ve $5537.5 \mathrm{MHz})$ CST STUDIO SUITE 2021 kullanılarak gerçekleştirilmiştir. EM alan kaynağı olarak kullanılan anten dizisi, her bir insan modeli için kulağa aynı uzaklık ve açıda (konuşma pozisyonunda) yerleştirilmiş ve aynı güç değeri için SAR $(10 \mathrm{~g})$ değerleri hesaplanmıştır. Frekansa bağlı olarak SAR $(10 \mathrm{~g})$ değerlerinin doğru biçimde hesaplanabilmesi için hesaplamalı insan modellerine ait tüm dokuların dielektrik özellikleri çalışma frekansina uygun olarak değiştirilmiştir. Tablo 2'den görüldüğü gibi, tüm kafa için $3600 \mathrm{MHz}$ 'de hesaplanan SAR (10g) değeri çocuk hesaplamalı insan modelinde, yetişkin erkek ve kadına göre daha yüksektir. $5537.5 \mathrm{MHz}$ frekansında ise yetişkin erkek beyninde, yetişkin kadına göre $\% 4.16$ oranında daha yüksek SAR $(10 \mathrm{~g})$ değeri elde edilirken, çocuk modeli için bu oran $\% 11.11$ dir. Tablo 2'de yer alan değerler incelendiğinde, SAR $(10 \mathrm{~g})$ değerlerinin dokuların dielektrik özelliklerine bağlı olarak değişimi de rahatlıkla gözlenebilmektedir.
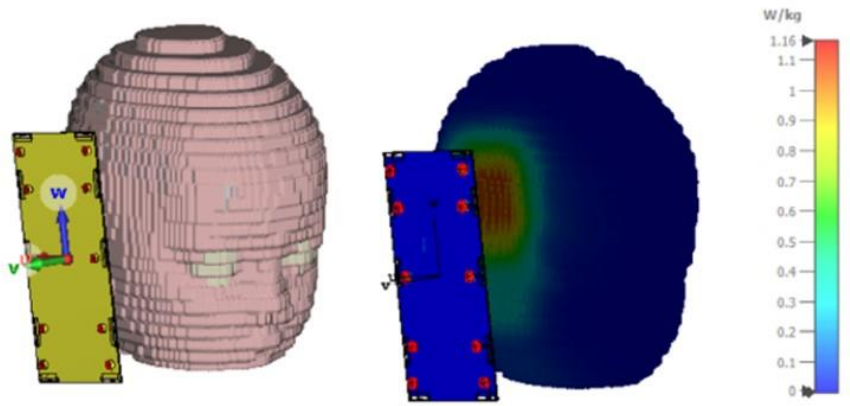

(a)
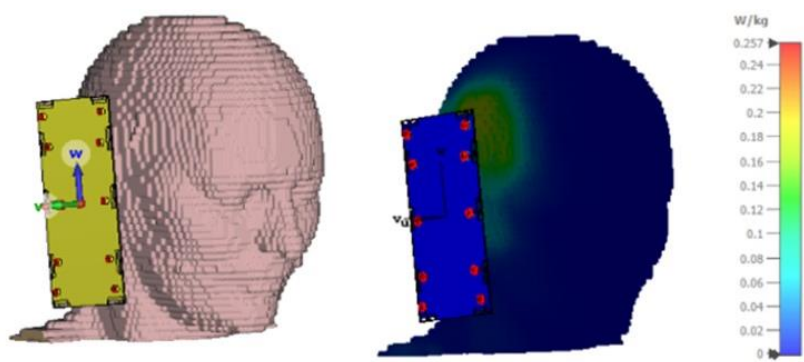

(b) 

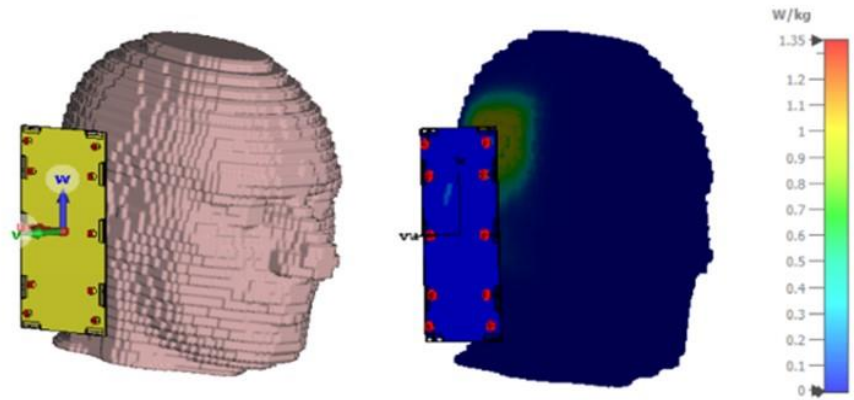

(c)

Şekil 5. Hesaplamalı insan modelleri için SAR (10g) dă̆ılımı a) Çocuk (Child) b) Kadın (Laura) c) Erkek (Gustav)

Tablo 2.Tüm Kafa ve Dokular İçin SAR (10g) Değerleri

\begin{tabular}{|c|c|c|c|c|c|c|c|c|}
\hline \multirow{2}{*}{} & \multicolumn{3}{|c|}{$3600 \mathrm{MHz}$} & \multicolumn{3}{c|}{$5537.5 \mathrm{MHz}$} \\
\cline { 2 - 9 } & \multicolumn{3}{|c|}{ SAR(10g) W/kg } & \multicolumn{3}{c|}{ SAR(10g) W/kg } \\
\cline { 2 - 9 } & $\begin{array}{l}\text { Tüm } \\
\text { Kafa }\end{array}$ & Beyin & Kemik & Deri & $\begin{array}{l}\text { Tüm } \\
\text { Kafa }\end{array}$ & Beyin & Kemik & Deri \\
\hline $\begin{array}{c}\text { Yetişkin } \\
\text { Erkek }\end{array}$ & 1.19 & 0.89 & 1.05 & 1.19 & 0.81 & 0.5 & 0.73 & 0.81 \\
\hline $\begin{array}{c}\text { Yetişkin } \\
\text { Kadın }\end{array}$ & 0.39 & 0.26 & 0.299 & 0.39 & 0.81 & 0.48 & 0.81 & 0.81 \\
\hline Çocuk & 1.7 & 1.7 & 1.7 & 1.7 & 0.67 & 0.45 & 0.55 & 0.67 \\
\hline
\end{tabular}

\section{Sonuç}

Bu çalışmada, ( $\mathrm{Li}$ et al., 2018)'de verilen ve $3400 \mathrm{MHz}-$ $3600 \mathrm{MHz}$ ve $5150 \mathrm{MHz}-5925 \mathrm{MHz}$ frekans aralıklarında çalışan, 10-portlu bir MIMO anten sisteminin optimizasyonu güven aralığı çerçevesi algoritması ile yapılmış ve LTE $42 / 43$ ve LTE 46 bantlarında uygun yansıma katsayıları elde edilmiştir. Yeniden boyutlandırılan anten dizisi ve farklı hesaplamalı insan modelleri kullanılarak SAR(10g) hesaplamaları CST kullanılarak yapılmıştır. Elde edilen sonuçlardan, genel olarak tüm hesaplamalı insan modellerinde en yüksek etkinin deri dokusunda oluştuğu, bunu kemik ve beyin dokularının izlediği görülmüştür. Kemik dokusu için $3600 \mathrm{MHz}$ frekansında en yüksek SAR $(10 \mathrm{~g})$ değeri çocuk hesaplamalı insan modelinde görülürken, $5537.5 \mathrm{MHz}$ frekansında en yüksek değer yetişkin kadın hesaplamalı insan modelinde gözlemlenmiştir. Hesaplanan SAR $(10 \mathrm{~g})$ değerlerinin ICNIRP tarafindan belirlenen limit değerden $(2 \mathrm{~W} / \mathrm{kg})$ daha düşük olduğu belirlenmiştir.

\section{Kaynakça}

Dong, J., Wang, S., \& Mo, J. (2020). Design of a twelve-port mimo antenna system for multi-mode $4 \mathrm{~g} / 5 \mathrm{~g}$ smartphone applications based on characteristic mode analysis. IEEE Access, 8, 90751-90759.

Koga, Y., Kai, M., Fujieda, K., \& Egawa, H. (2016, September). Design of a low SAR multiband antenna for mobile applications. In 2016 IEEE-APS Topical Conference on Antennas and Propagation in Wireless Communications (APWC) (pp. 47-50). IEEE.

Kumar, D. R., Babu, G. V., Narayan, K. S., \& Raju, N. (2021). Investigation of 10-port coupled fed slotted MIMO antenna system for $5 \mathrm{G}$ mobile handset. International Journal of Microwave and Wireless Technologies, 1-14.

Li, M. Y., Ban, Y. L., Xu, Z. Q., Guo, J., \& Yu, Z. F. (2017). Tripolarized 12-antenna MIMO array for future $5 \mathrm{G}$ smartphone applications. IEEE Access, 6, 6160-6170.

Li, Y., Luo, Y., \& Yang, G. (2018). Multiband 10-antenna array for sub-6 GHz MIMO applications in 5-G smartphones. IEEE access, 6, 28041-28053.

Parchin, N. O., Al-Yasir, Y. I. A., Ali, A. H., Elfergani, I., Noras, J. M., Rodriguez, J., \& Abd-Alhameed, R. A. (2019). Eightelement dual-polarized MIMO slot antenna system for $5 \mathrm{G}$ smartphone applications. IEEE access, 7, 15612-15622.

Sun, L., Feng, H., Li, Y., \& Zhang, Z. (2018). Compact 5G MIMO mobile phone antennas with tightly arranged orthogonal-mode pairs. IEEE Transactions on Antennas and Propagation, 66(11), 6364-6369.

Takei, R., Nagaoka, T., Saito, K., Watanabe, S., \& Takahashi, M. (2017). SAR variation due to exposure from a smartphone held at various positions near the torso. IEEE Transactions on Electromagnetic Compatibility, 59(2), 747-753.

Wong, K. L., \& Lu, J. Y. (2015). 3.6-GHz 10-antenna array for MIMO operation in the smartphone. Microwave and Optical Technology Letters, 57(7), 1699-1704.

Wong, K. L., Lu, J. Y., Chen, L. Y., Li, W. Y., \& Ban, Y. L. (2016). 8-antenna and 16-antenna arrays using the quad-antenna linear array as a building block for the 3.5-GHz LTE MIMO operation in the smartphone. Microwave and Optical Technology Letters, 58(1), 174-181.

Zhao, K., Zhang, S., Ying, Z., Bolin, T., \& He, S. (2013). SAR study of different MIMO antenna designs for LTE application in smart mobile handsets. IEEE Transactions on Antennas and Propagation, 61(6), 3270-3279.

Zhao, X., Yeo, S. P., \& Ong, L. C. (2018). Decoupling of inverted-F antennas with high-order modes of ground plane for 5G mobile MIMO platform. IEEE Transactions on Antennas and Propagation, 66(9), 4485-4495.

Zou, H., Li, Y., Sim, C. Y. D., \& Yang, G. (2018). D esign of $8 \times$ 8 dual-band MIMO antenna array for $5 \mathrm{G}$ smartphone applications. International Journal of RF and Microwave Computer-Aided Engineering, 28(9), e21420. 